\title{
Agonist versus antagonist protocol in induction of ovulation and its outcome
}

\author{
Prasad Lele $^{1 *}$, Raju Agarwal' ${ }^{2}$, Chuni Selden ${ }^{3}$
}

\author{
${ }^{1}$ Department of Obstetrics and Gynecology, CH (CC), King Gorge Medical University, Lucknow, India \\ ${ }^{2}$ Department of Obstetrics and Gynecology, AFMC, Pune \\ ${ }^{3}$ Gynaecologist, Royal Bhutan Army, Thimpu, Bhutan
}

Received: 05 April 2016

Accepted: 23 May 2016

\section{*Correspondence:}

Dr. Prasad Lele,

E-mail: prasadlele@ hotmail.com

Copyright: $\odot$ the author(s), publisher and licensee Medip Academy. This is an open-access article distributed under the terms of the Creative Commons Attribution Non-Commercial License, which permits unrestricted non-commercial use, distribution, and reproduction in any medium, provided the original work is properly cited.

\begin{abstract}
Background: Gonadotropin-releasing hormone $(\mathrm{GnRH})$ antagonist produces immediate suppression of gonadotrophins secretion without the initial stimulatory effect of premature luteinizing hormone (LH) .The aim of the study was to compare the agonist and the antagonist protocol in the induction of ovulation.

Methods: The study is a comparative study conducted from 01 November 2011 to 31 August 2013. All patients of primary or secondary infertility underwent a baseline transvaginal sonography on day 2 or day 3rd of the menstrual cycle for follicle count and endometrial thickness. All patients received oral contraceptive pills from day 5 for 21 days of menstrual cycle and were assigned to two categories; the agonist and the antagonist group.

Results: A total of 380 patients, 190 patients of agonist group 52 had a positive $\beta$ hCG (human chorionic gonadotropin) report (27.3\%) compared to the 60 patients of 190 antagonist group (31.5\%). The P value was 0.44 which is statistically insignificant. Age group were similar and mean age of agonist group was $27.96+3.21$ where as in antagonist group $28.11+3.24$. The number of oocyte retrieved was found to be better in the antagonist group compared to agonist group (mean \pm sd $10.71+6.41$ versus $8.62 \pm 5.65$, $\mathrm{P}$ value $<0.001$ ). The patients in the agonist group had a slightly more number of transfers performed (2.78 \pm 0.94$)$, in comparison to the antagonist group $(2.75 \pm 0.97)$. Pvalue was 0.789 which was statistically insignificant.

Conclusions: The GnRH antagonist therefore seems to be a more patient friendly protocol for the first choice in ART cycle with lower incidence of side effects and similar pregnancy rate. It is also time saving and simple protocol with good clinical outcome.
\end{abstract}

Keywords: GnRH antagonist, Agonist, LH, FSH, hCG, Endometrium thickness

\section{INTRODUCTION}

It has been well-known of GnRH from back to the early $20^{\text {th }}$ century, when it was discovered that lesions of the anterior pituitary gave rise to genital atrophy, thereby identifying the pituitary-gonadal axis.

Ascheim and Zondek demonstrated the stimulation of gonadal function with urine derived from pregnant women, in 1928. ${ }^{1}$ Three years later, Fevold provided the first convincing evidence of two gonadotropins, subsequently leading to the purification of FSH (follicle stimulating hormone) and $\mathrm{LH}^{2}$ Over the next 30 years, limited success was seen for attempts on ovarian stimulation with exogenous preparation due to antibody formation and safety concern.

Pregnant mare's serum and extracts of the human pituitary gland were used. ${ }^{3,4}$ The concept of the 'two step protocol' was introduced in 1941. Ovarian stimulation using gonadotropins (pregnant mares serum gonadotropin, hog or sheep pituitary gonadotropins) was started to stimulate the follicular growth and development, followed by the induction of ovulation using hCG. 
By 1960, FSH and LH were extracted from the urine of postmenopausal women. These preparations were routinely used to stimulate ovarian function although there was still significant contamination with impurities causing batch to batch variability and poorly predictive responses. ${ }^{5}$

In 1971, the GnRH decapeptide was isolated and its structure elucidated. By 1978, the initial flare response to GnRH agonist (GnRH1a) followed by pituitary GnRH receptor down regulation was clarified. ${ }^{6}$

Pregnancy was first reported in a woman with hypogonadotrophic hypogonadism, using pulsatile low dose GnRH1a, in $1978 .^{7}$ By the 1980s, GnRH1a was used to prevent the LH surge during ovarian stimulation. ${ }^{8}$ The long down regulation protocol with GnRH1a established the IVF practice. A reduction in the cycle cancellation rate from $15-20 \%$ to $2 \%$ was seen.

GnRH1a has remained the ''gold standard' protocol for ovulation induction for more than 20 years until recently with the introduction of GnRH antagonist (April 1999 in the UK and May 2000 in North America) presented opportunities to develop novel, milder approaches for ovulation stimulation in IVF. The GnRH antagonist (GnRH ant) offered several advantages such as lesser incidence of hyper stimulation syndrome, shorter duration of treatment, less aggressive protocol and as a surrogate for ovulation.

The GnRH1a used in the long protocol lead to pituitary desensitization only after 2-3 weeks of treatment, because of the initial flare- up effect, which may lead to ovarian cyst formation. There are seven agonist analogues that are approved and clinically used: Leuprorelin, Buserelin, Goserelin, Histrelin, Deslorelin, Nafarelin, and Triptorelin.

On the other hand GnRH antagonist causes an immediate suppression of gonadotrophins secretion, without the initial stimulatory effect therefore can be started after the gonadotrophins administration. GnRH antagonist is administered by subcutaneous injections such as cetrorelix and ganilelix.

The aim of the study was to compare the agonist and the antagonist protocol in the induction of ovulation.

\section{METHODS}

\section{Patient population}

The study is a comparative study conducted from 01 November 2011 to 31 August 2013and comprised a population of 380 women coming to ART centre tertiary care hospital. Patients were assigned to two categories; the agonist and the antagonist group.
All patients with primary or secondary infertility underwent a baseline transvaginal sonography (TVC) on day $2^{\text {nd }}$ or day $3^{\text {rd }}$ of the menstrual cycle to check for antral follicle count (AFC) and endometrial thickness (ET) and to rule out the presence of ovarian cyst. All patients received oral contraceptive pills from day 5 for 21 days in that cycle. Patients were randomly assigned on the day to agonist or antagonist group and taken for IVF.

\section{Agonist group}

Patients were called on day 2 of the menstrual cycle and started with Inj. leuprolide acetate $0.5 \mathrm{mg}$ subcutaneously once daily (0800-1000 hours) till down regulation was achieved. Day 2 of the menstrual cycle was confirmed by serum estradiol $\left(\mathrm{Sr} \mathrm{E}_{2}\right)<50 \mathrm{pg} / \mathrm{ml}, \mathrm{ET}<4 \mathrm{~mm}$, no cyst in the ovaries and $\mathrm{Sr} \mathrm{LH}<3.0 \mathrm{IU} / \mathrm{L}$.

If down regulation was not achieved, treatment was continued further. Once down regulation was achieved inj. leuprolide dosage was reduced to $0.25 \mathrm{mg}$ daily and recombinant FSH (r-FSH) (GONAL-f, Merk-Sereno) was started.

The starting dose of r-FSH was 150-225 IU depending on the AFC. The dose was adjusted after 4 days of stimulation depending on the ovarian response, assessed by transvaginal scan (TVS) and $\mathrm{Sr} \mathrm{E}_{2}$.

Human menopausal gonadotropin (HMG) (HUMOG Bharat Serum) was added in the later days of the stimulation on an individual basis according to physician's discretion. Follicular growth was monitored by serial TVS. The dose of r-FSH and HMG was adjusted according to dynamics of ovarian follicular growth. Once the follicular size $>18 \mathrm{~mm}$ or two follicles on either side; Inj hCG (10,000 IU) was given intramuscular. Ovum pick up was done after 33-35 hours later.

\section{Antagonist group}

Inj r-FSH was started on day 2 of the cycle (150-225 IU /SC daily between $1600-1800$ hours). TVS was done after 4 days. If the ET was $>6 \mathrm{~mm}$ or the lead follicular size reached a diameter $>14 \mathrm{~mm}$, Inj. Cetrorelix $(0.2 \mathrm{mg})$ s/c (Cetrotide - Merk Sereno) (0800- 1000 hours) was started along with Inj. r- FSH. Dosage of Inj r-FSH was increased by $75 \mathrm{IU}$.

Follicular monitoring was done by TVS. Once two or more follicles of size $18 \mathrm{~mm}$ or more were seen on either side, final oocyte maturation trigger was given with Inj hCG 10,000 IU intramuscular.

Oocyte retrieval was performed 33-35 hours after the hCG injection by TVS- guided single-lumen needle aspiration. Oocyte assessment was performed by standard morphology criteria proposed by Lin et al., and nuclear maturity assessment was performed in cases subjected to intracytoplasmic sperm injection (ICSI). 
Conventional IVF or ICSI was performed depending on the semen parameters and previous fertilization history. Culture media used was Medicult. Fertilization check was done after 24 hours (defined as presence of two pronuclei). The embryo was transferred to ISM (Medicult) media after 24 hours.

Embryo grading was done by standard morphology assessment according to Gardners' scoring. Embryo Transfer was done on Day 2, 3 and 5 following oocyte retrieval.

All patients were prescribed $100 \mathrm{mg}$ micronized progesterone (I/M) as luteal phase support for 2 weeks. Serum $\beta \mathrm{hCG}>50 \mathrm{IU} / \mathrm{L}$ after fifteen days of embryo transfer was considered as positive for pregnancy.

\section{Inclusion criteria}

- $\quad$ Age $18-39$ years

- Menstrual cycle from $24-35$ days

- Normal basal FSH $<10 \mathrm{IU} / \mathrm{ml}$

- Normal basal LH <10 IU/ml

\section{Exclusion criteria}

- Endometriosis

- Premature ovarian failure

- Poor ovarian reserve

\section{Type of outcome measures}

Primary outcome

- Ovarian response

- Endometrial response

- Implantation rate

- Pregnancy rate in both groups

\section{Secondary outcome}

- Duration of stimulation

- Number of follicles

- Endometrial thickness

- Number of oocytes retrieved

- Number of transferred embryos

\section{RESULTS}

A total of 380 women were involved in the study after applying the inclusion and exclusion criteria. Out of the 190 patients in the agonist group 52 patients had a positive $\beta$ hCG report $(27.3 \%)$ compared to the 60 patients of 190 antagonist group $(31.5 \%)$. The $\mathrm{P}$ value was 0.44 which is statistically insignificant as shown in Table 1.

Age group of patients was similar in both the groups. The agonist group had patients with a mean age 27.9; SD
3.21, whereas antagonist group mean age was 28.11; SD 3.24 (Table 2).

Table 1: HCG findings.

\begin{tabular}{|c|c|c|c|c|}
\hline $\begin{array}{l}\text { Pregnancy } \\
\text { test }\end{array}$ & Group & & Total & $\begin{array}{l}\text { P- } \\
\text { value }\end{array}$ \\
\hline & Agonist & Antagonist & & \\
\hline Positive & 52 & 60 & 112 & 0.431 \\
\hline Negative & 138 & 130 & 268 & \\
\hline total & 190 & 190 & 380 & \\
\hline
\end{tabular}

By using Chi-square test p-value $>0.05$ therefore there is no association between pregnancy test with respect to agonist and antagonist.

Table 2: Age of the patients (years).

\begin{tabular}{|lllll|}
\hline & $\begin{array}{l}\text { Number of } \\
\text { patients }\end{array}$ & $\begin{array}{l}\text { Age } \\
\text { Mean }\end{array}$ & SD & p-value \\
\cline { 1 - 4 } Agonist & 190 & 27.98 & 3.21 & \multirow{2}{*}{0.715} \\
\cline { 1 - 4 } Antagonist & 190 & 28.11 & 3.24 & \\
\hline
\end{tabular}

By using 2 independent sample t-test $\mathrm{p}$-value $>0.05$ therefore there is no significant difference between mean age (years) in agonist group and antagonist group.

The duration of stimulation was observed to be shorter in the antagonist group (8.22 days, SD 1.68). This indicated a lesser number of gonadotrophins used in total. This protocol was more patient friendly as the number of injections was comparatively lesser. The patients in the agonist group however had to undergo stimulation with gonadotropins for a longer duration (9.91 days, SD 1.92) (Table 3).

Table 3: Age of the patients (years).

\begin{tabular}{|llll|l|}
\hline & $\begin{array}{l}\text { Number of } \\
\text { patients }\end{array}$ & \multicolumn{2}{l}{$\begin{array}{l}\text { Duration of } \\
\text { stimulation }\end{array}$} & p-value \\
\cline { 1 - 4 } & & Mean & SD & \\
\cline { 1 - 4 } Agonist & 190 & 9.91 & 1.92 & 0.141 \\
\cline { 1 - 4 } Antagonist & 190 & 8.22 & 1.68 & \\
\hline
\end{tabular}

By using 2 independent sample t-test p-value $>0.05$ therefore there is no significant difference between mean duration for stimulation in agonist and antagonist group

Table 4: Endometrial thickness.

\begin{tabular}{|lllll|}
\hline & $\begin{array}{l}\text { Number } \\
\text { of patients }\end{array}$ & \multicolumn{2}{l}{$\begin{array}{l}\text { Endometrial } \\
\text { Thickness }\end{array}$} & p-value \\
\cline { 2 - 4 } & & Mean & SD & \\
\cline { 1 - 4 } Agonist & 190 & 9.13 & 1.44 & 0.001 \\
\cline { 1 - 4 } Antagonist & 190 & 8.66 & 1.22 & \\
\hline
\end{tabular}

By using 2 independent sample t-test, $\mathrm{p}$-value $<0.05$ therefore there is significant difference between mean endometrial thickness in agonist group and antagonist group.

This later group also had to be under more constant supervision for hyperstimulation. The effect on the endometrial thickness with the exogenous stimulation was found to be comparatively better with the agonist 
group as compared to the patients in the antagonist group (mean $9.13 \pm 1.44 \mathrm{~mm}$ versus $2.66 \pm 1.22 \mathrm{~mm}$; $\mathrm{P}$ value 0.001) (Table 4).

The number of oocyte retrieved was found to be better in the antagonist group in comparison to the agonist group (mean 10.71; SD 6.41 versus mean 8.62; SD 5.65, P value $<0.001)$ (Table 5).

\section{Table 5: Oocyte retrieval.}

\begin{tabular}{|c|c|c|c|c|}
\hline & \multirow[t]{2}{*}{$\begin{array}{l}\text { Number } \\
\text { of patients }\end{array}$} & \multicolumn{2}{|c|}{$\begin{array}{l}\text { Number of } \\
\text { oocyte } \\
\text { retrieval }\end{array}$} & \multirow[t]{2}{*}{ p-value } \\
\hline & & Mean & SD & \\
\hline Agonist & 190 & 10.71 & 6.41 & \multirow[t]{2}{*}{0.001} \\
\hline Antagonist & 190 & 8.62 & 5.65 & \\
\hline
\end{tabular}

By using 2 independent sample t-test, $\mathrm{p}$-value $<0.05$ therefore there is significant difference between mean number of oocyte retrieval in agonist group and antagonist group.

However, the number of embryos transferred in both the group was comparable. The patients in the agonist group had a slightly more number of transfers done $(2.78 \pm 0.94)$, in comparison to the antagonist group $(2.75 \pm 0.97)$. Pvalue was 0.789 which was statistically insignificant (Table 6).

Table 6: Embryos transferred.

\begin{tabular}{|lllll|}
\hline & $\begin{array}{l}\text { Number of } \\
\text { patients }\end{array}$ & $\begin{array}{l}\text { No. of } \\
\text { embryos }\end{array}$ & p-value \\
& & $\begin{array}{l}\text { Mransferred } \\
\text { tran }\end{array}$ & SD & \\
\hline Agonist & 190 & 2.78 & 0.94 & 0.789 \\
\cline { 1 - 4 } Antagonist & 190 & 2.75 & 0.97 & \\
\hline
\end{tabular}

By using 2 independent sample t-test p-value $>0.05$ therefore there is no significant difference between mean no. of embryos transferred in agonist and antagonist group.

Table 7: Side effects (ovarian hyperstimulation syndrome).

\begin{tabular}{|llllll|}
\hline $\begin{array}{l}\text { Side } \\
\text { effect }\end{array}$ & $\begin{array}{l}\text { Group } \\
\text { Agonist }\end{array}$ & Antagonist & Total & $\begin{array}{l}\text { P- } \\
\text { value }\end{array}$ \\
\hline Yes & 16 & 4 & 20 & \multirow{2}{*}{0.006} \\
\hline No & 174 & 186 & 360 & \\
\hline Total & 190 & 190 & 380 & \\
\hline
\end{tabular}

By using Chi-square test $p$-value $<0.05$ therefore there is association between the side effect with respect to agonist and antagonist.

The incidence of ovarian hyperstimulation syndrome was found to be significantly higher in the agonist group. 20 patients in the agonist group were admitted for severe ovarian hyperstimulation syndrome, whereas only 4 patients were affected in the antagonist group. The patients were managed conservatively (Table 7).

\section{DISCUSSION}

Several studies have directly compared these two stimulation protocols mainly in terms of pregnancy rate and incidence of ovarian hyperstimulation syndrome (OHSS).

According to Kolibianakis et al based on the analysis of 22 published RCTs, compared the effectiveness of GnRH agonist and GnRH antagonists in IVF with respect to the probability of live birth per patient randomized, and concluded that the probability of live birth between agonists and antagonists was not significantly different. ${ }^{9}$

Despite the theoretical advantages of GnRH antagonists, their use was hampered due to the results obtained in a cochrane review of the initial five randomized studies, which indicated a trend towards slightly lower implantation and pregnancy rates for the $\mathrm{GnRH}$ antagonist treatment group compared to those in the GnRH agonist group was reported by Al-Inany and Aboulghar. ${ }^{10}$

Al-Inany et al has included 27 randomized controlled trials where it was seen that the clinical pregnancy rate and the ongoing pregnancy/live-birth rate was seen to be significantly lower in the antagonist group. ${ }^{11}$

However, in a retrospective study by Natalia PM et al, using ganirelix and leuprolide acetate; results showed that the implantation rate (15\% versus $6 \%$ ) and the clinical pregnancy rate $(27 \%$ versus $12 \%)$ was significantly higher in the ganirelix group compared to the leuprolide group. ${ }^{12}$

In a phase III, multicentre, open-label randomized trial conducted by Fluker $\mathrm{M}$ et al, where 313 women were randomized to receive one $\mathrm{COH}$ cycle with ganirelix or a long protocol of leuprolide acetate. ${ }^{13}$ The study concluded similar pregnancy rates in both the groups. Fertilization rates were $62.4 \%$ and $61.9 \%$ in the ganirelix group and leuprolide group respectively, and the implantation rates were $21.1 \%$ and $26.1 \%$. Clinical and ongoing pregnancy rates were $35.4 \%$ and $30.8 \%$ in the ganirelix group and $38.4 \%$ and $36.4 \%$ in the other.

The current study also shows a slightly higher pregnancy rate in the antagonist group in comparison to the agonist, thought the difference is insignificant.

Studies have also included the comparison of the duration of days involved in the ovarian stimulation in both the groups. In a retrospective study by Natalia PM conducted from 1999 to 2001, comparing the clinical outcome using ganirelix acetate and leuprolide acetate, it was seen that ganirelix reduces the duration and amount of gonadotrophins and the day of HCG trigger was 4 days earlier. 
Olivennes et al in a RCT showed that the average duration of stimulation was significantly less with cetrorelix than with triptorelin (9.4 versus 10.7 days). ${ }^{14}$

Tehraninejad et al, conducted a randomized clinical trial where he compared buserelin acetate with cetrorelix. He concluded that the duration of stimulation in agonist group was significantly higher than antagonist group $(9.6 \pm 1.6$ vs. $8.2 \pm 1.6$ days, $\mathrm{p}=0.00){ }^{15}$

The current study also shows a similar result. The duration of ovarian stimulation was found to be significantly shorter in the antagonist group, therefore, requiring lesser number of gonadotrophins. The number of injections in total that the patient takes is also reduced. These advantages make the antagonist protocol more patients friendly.

However, in another RCT conducted by Murber et al, the mean number of days for ovarian stimulation needed was 10.9 in the antagonist group and 10.2 in the agonist group and was not significantly different between the two groups. He also concluded that there was no difference in the mean number of retrieved oocytes between the antagonist and the agonist group (11 versus 11.2 oocytes). ${ }^{16}$

A randomized trial conducted by Fluker $\mathrm{M}$ et al also showed that the mean number of oocytes retrieved per attempt was 11.6 in the ganirelix group and 14.1 in the leuprolide group. ${ }^{13}$

Total retrieved oocytes and mature or metaphase II oocytes were seen to be greater in the agonist group, in a randomized control trial by Olivennes et al, where he compared triptorelin with cetrolelix. ${ }^{14}$

In a study by Chang et al, the antagonist group (ganirelix) showed a higher number of oocytes retrieved compared to the agonist group $(7.7 \pm 0.8$ versus $5.3 \pm 0.7, \mathrm{P}<0.05){ }^{17}$ In a prospective case control study by Minaretzis D et al, there was no difference in the number of retrieved oocytes, but the antagonist group had a higher proportion of mature oocytes, $82 \% \pm 4 \%$ versus $62.4 \%(\mathrm{p}=0.02)$, and a higher proportion of embryos of good quality, $69.8 \% \pm 9.8 \%$ versus $44.3 \% \pm 7.2 \%(\mathrm{p}=0.03)$ in the agonist group. ${ }^{18}$

The current study also shows a higher number of oocyte retrieval on the antagonist group but the number of embryo transferred is comparable in both the groups.

Tehraninejad et al, conducted a randomized clinical trial where he compared buserelin acetate with cetrorelix showed significant difference between two groups regarding endometrial thickness on the day of HCG $(10.3 \mathrm{~mm}$ in agonist vs. $9.3 \mathrm{~mm}$ in antagonist group, $\mathrm{p}=$ $0.00){ }^{15}$
Ovarian hyperstimulation syndrome, a serious life threatening complication is an exaggeration of the normal ovarian physiology. Its intensity is related to the degree of ovarian response to ovulation induction therapy.

This incidence of this serious complication has been found to be higher in the antagonist group, $\mathrm{P}$ value of 0.006 , in this study. This is in accord to the studies conducted by Ludwig et al, where a statistically significant reduction in its incidence with the antagonist protocol as compared to the agonist has been seen. ${ }^{19}$

Similarly, a recent review Al-Inany et al confirmed that there is a statistically significant reduction in the incidence of severe OHSS with the antagonist protocol, even with the interventions to prevent it (e.g. coasting, cycle cancellation). ${ }^{11}$

A prospective, randomized study performed by Ludwig $M$ et al, compared buserelin with cetrorelix, the incidence of ovarian hyperstimulation syndromes (OHSS) was significantly lower in the cetrorelix than in the buserelin group $(1.1 \%$ versus $6.5 \%, \mathrm{p}=0.03){ }^{19}$

According to Al-Inany et al including 45 RCT comparing $\mathrm{GnRH}$ antagonist to GnRH agonist long protocol. According to this review a reduction in incidence of OHSS can be observed in the GnRH antagonist group. ${ }^{20}$

\section{CONCLUSION}

The results of this study show that these two protocols are very similar in outcomes in normoresponder patients. Immediate mode of action, flexibility of use, shorter duration of administration, shorter duration of FSH stimulation, and a lower incidence of hospital admission due to severe OHSS make the antagonist protocol an excellent approach for ovarian stimulation in IVF.

Literature suggests that the side effect, physiologic and psychological distress and treatment burden is lower in antagonist protocol, though these points were not concerned in the present study.

The GnRH Antagonist therefore seems to be a more patient friendly protocol for the first choice in ART cycle with lower incidence of side effects and similar pregnancy rate. It is a time saving with similar outcomes of standard agonist protocol.

Funding: No funding sources Conflict of interest: None declared

Ethical approval: The study was approved by the Institutional Ethics Committee

\section{REFERENCES}

1. Ascheim S, Zondek B. Hypophysenvorderlaooen hormone und ovarial hormone imHarn von Schargeren. KlinischeWochenschrift. 1927;6:13-21. 
2. Fevold SL, Hisaw FL, Leonard SL. The gonadstimulating and the luteinizing hormone of the anterior lobe of the hypophysis. American Journal of Physiology. 1931;97:291-301.

3. Hamblen EC. Endocrine therapy of functional ovarian failure. American Journal of Obstetrics and Gynecology. 1940;40:615-62.

4. Gemzell CA. Induction of ovulation with pituitary gonadotrophins. Fertility and Sterility. 1962;13:15368.

5. Hayden CJ, Balen AH, Rutherford AJ. Recombinant gonadotrophins. British Journal of Obstetrics and Gynaecology. 1999;106:188-96.

6. Conn PM, Crowley WF Jr. Gonadotropin-releasing hormone and its analogs. Annual Review of Medicine. 1994;45:391-405.

7. Gorgeon A, Lefevre B. Evaluation of the largest healthy and atretic follicle during the human menstrual cycle. J Reprod Fertil. 1983;69:497-502.

8. Leyendecker G, Wildt L, Hansmann M. Pregnancies following chronic intermittent (pulsatile) administration of Gn-RH by means of a portable pump ('Zyklomat') - a new approach to the treatment of infertility in hypothalamic amenorrhea. Journal of Clinical Endocrinology and Metabolism. 1980;51:1214-6.

9. Kolibianakis EM, Papanikolaou EG, Camus M, Tournaye H, Van Steirteghem AC, Devroey P. Effect of oral contraceptive pill pretreatment on ongoing pregnancy rates in patients stimulated with GnRH antagonists and recombinant FSH for IVF. A randomized controlled trial. Hum Reprod. 2006;21:352-7.

10. Al-Inany $\mathrm{H}$ and Aboulghar $\mathrm{M}$. GnRH antagonist in assisted reproduction: a Cochrane review. Hum Reprod. 2002;17:874-85.

11. Al-Inany HG, Abou-Setta AM, Aboulghar M. Gonadotrophin-releasing hormone antagonists for assisted conception. Cochrane Database Syst Rev. 2006;(3):CD001750.

12. Natalia PM, Vlahos NP, Jurema MW, Bracero NJ, Wallach EE, Garcia JE Clinical outcome of using ganirelix acetate versus a 4-day follicular phase leuprolide acetate protocol in unselected women undergoing in vitro fertilization. Fertility and sterility. 2003;80(1):103-10.

13. Fluker M, Grifo J, Leader A, Levy M, Meldrum D, Muasher SJ, Rinehart J. Efficacy and safety of ganirelix acetate versus leuprolide acetate in women undergoing controlled ovarian hyperstimulation. Fertil Steril. 2001;75(1):38-45.

14. Olivennes F, Belaisch-Allart J, Emperaire JC, Dechaud H, Alvarez S, Moreau L, et al. Prospective, randomized, controlled study of in vitro fertilizationembryo transfer with a single dose of a luteinizing hormone-releasing hormone (LH-RH) antagonist (cetrorelix) or a depot formula of an LH-RH agonist (triptorelin). Fertil Steril. 2000;73:314-20.

15. Tehraninejad E, Nezamabadi AG, Rashidi B, Sohrabi M, Bagheri M, Haghollahi F, et al. GnRH antagonist versus agonist in normoresponders undergoing ICSI: a randomized clinical trial in Iran. Iran J Reprod Med. 2011;9(3):171-6.

16. Murber A, Fancsovits P, Ledó N, Gilán ZT, Rigó JJr, Urbancsek J. Impact of GnRH analogues on oocyte/embryo quality and embryo development in in vitro fertilization/intracytoplasmic sperm injection cycles: a case control study.2009;7:103.

17. Chang MC. Fertilization and normal development of follicular oocytes in the rabbit. Science. 1955; 121:867.

18. Minaretzis D, Harris D, Alper MM, Mortola JF, Berger MJ, Power D. Multivariate Analysis of Factors Predictive of Successful Live Births in In Vitro Fertilization (IVF) Suggests Strategies to Improve IVF Outcome. Journal of Assisted Reproduction and Genetics. 1998;15(6):365-71.

19. Ludwig M, Felberbaum RE, Devroey P, Albano C, Riethmüller-Winzen $\mathrm{H}$, Schüler $\mathrm{A}$, et al. Arch Gynecol Obstet. Significant reduction of the incidence of ovarian hyperstimulation syndrome (OHSS) by using the LHRH antagonist Cetrorelix (Cetrotide) in controlled ovarian stimulation for assisted reproduction. 2000;264(1):29-32.

20. Al-Inany HG, Youssef MA, Aboulghar M, Broekmans F, Sterrenburg M, Smit J, Abou-Setta AM. Gonadotrophin-releasing hormone antagonists for assisted reproductive technology. Cochrane Database Syst Rev. 2011:CD001750.

Cite this article as: Lele $\mathrm{P}$, Agarwal $\mathrm{R}$, Selden $\mathrm{C}$. Agonist versus antagonist protocol in induction of ovulation and its outcome. Int J Reprod Contracept Obstet Gynecol 2016;5:1748-53. 